\title{
The Human NGFI-B Gene Gives Rise to Two Isoforms with Different Expression Profiles
}

\author{
Naganari Ohkura, Tetsuji Hosono, Kouj Maruyama, Toshihiko Tsukada and Ken Yamaguchi \\ Growth Factor Division, National Cancer Center Research Institute, 5-1-1 Tsukiji, Chuo-ku, Tokyo 104-0045, Japan
}

(Received 1 September 1999; and accepted 15 September 1999)

\begin{abstract}
NGFI-B is an immediate-early gene that belongs to the steroid/thyroid receptor superfamily. In this study, we cloned and characterized a human NGFI-B isoform designated NGFI-B2, which has a unique 5'-untranslated region and which lacks C-terminal amino acid sequences corresponding to the putative ligand-binding or dimerizing domain. The NGFI-B and NGFI-B2 mRNAs are differentially expressed in human tissues. To study the transcriptional regulation of these isoforms, we examined the effects of forskolin and 12-O-tetradecanoylphorbol-13-acetate (TPA) on their expression in human neuroblastoma and breast cancer cells. NGFI-B, but not NGFI-B2 transcripts were rapidly induced, suggesting that NGFI-B2 is not associated with the immediate-early response. The expression and regulation of the NGFI-B isoforms suggested that they are expressed by separate promoters, and that they play different roles in biological processes.
\end{abstract}

NGFI-B (9) [also known Nur77 (4), N10 (15), NAK 1 (10) and TR3 (1)] is an immediate-early gene that was originally identified by virtue of its rapid activation by serum stimulation of quiescent fibroblasts. It is also activated by such diverse signals as membrane depolarization and nerve growth factor (NGF) in $\mathrm{PCl} 2$ pheochromocytoma cells and by chemically induced seizure in hippocampal neurons (17). NGFI-B belongs to the steroid/thyroid receptor superfamily and it potently activates transcription through interactions with DNA at sequence-specific sites (18). Studies of NGFI-B expression suggest that it plays important roles in the central and peripheral nervous systems and in steroidogenic organs $(3,13)$. Furthermore, since the expression of "dominant negative" NGFI-B or

Correspondence to: Dr Naganari Ohkura, at the above address.

Tel: +81 3-3542-2511 ext.4302

Fax: $+813-3542-8170$

E-mail:nohkura@gan2.ncc.go.jp
NGFI-B antisense transcripts prevents the activation-induced apoptosis of T-cells, NGFI-B might be involved in control of the activationinduced apoptosis of thymocytes and T-cell hybridomas $(7,19)$.

In this paper we show that the human NGFI-B gene gives rise to two distinct mRNAs, which were differentially expressed in tissues, and induced by stimulation in human neuroblastoma and breast cancer cells.

\section{MATERIALS AND METHODS}

\section{Cloning of the isoform}

A cDNA fragment encoding the DNA-binding domain of human NOR-1 was labeled with DIGdUTP (Boehringer Mammheim) by PCR. A human skeletal muscle cDNA library in $\lambda$ gt 11 (Stratagene) was screened with the labeled fragment and we isolated a cDNA encoding a sequence similar to those of nuclear receptors. The cDNA was sequenced by means of dideoxynucleotide chain-termination. 


\section{Reverse-transcriptase-PCR}

Transcripts of NGFI-B2 and NGFI-B were detected by means of reverse transcriptase-PCR (RT-PCR). All cDNAs were synthesized using $1 \mu \mathrm{g}$ of total RNAs and reverse transcriptase (Superscript II, BRL) with the P1 primer (5'GCAGCCGTACACCTGGAAGTCC-3'; for NGFI-B or NGFI-B2) or an oligo-dT primer [for glyceraldehyde 3-phosphate dehydrogenase (G3PDH)]. The 5' primers for amplification were 5'-CTTCGTGCGGTTGTCTGGGAC-3' for NGFI-B2 (nt 120-140; Fig. 1) and 5'GCACAGAAGAACTTCGGGAGCG-3' for NGFI-B [nt 18-39 (1)]. The 3' oligonucleotide primer was from their common transactivating domain and it contained a sequence (5'-AGCATGGCTGGACTGTTCCTGG-3') located immediately upstream of the primer used for reverse transcription. The single strand cDNA products were denatured and amplified by 40 PCR cycles. For control G3PDH cDNA amplification, the cDNA products were amplified by 35 PCR cycles with two primers (5'-CTTCACCACCATGGAGAAGGCTGG-3', 5' primer; 5'TCCAGGGGTCTTACTCCTTGGAGG-3, , 3' primer). Each cycle consisted of denaturation at $94{ }^{\circ} \mathrm{C}$ for $30 \mathrm{sec}$, annealing at $55^{\circ} \mathrm{C}$ for $75 \mathrm{sec}$ and extension at $72^{\circ} \mathrm{C}$ for $120 \mathrm{sec}$. The PCR products were confirmed by DNA sequencing.

\section{Cell culture and RNA isolation}

The human neuroblastoma cell line, NB-OK-1, and the breast cancer cell line, MCF7, were maintained in RPMI 1640 medium containing $10 \%$ fetal bovine serum (Mitsubishi Kasei). Cells (approximately $1 \times 10^{7}$ cells $/ 10 \mathrm{~cm}$ dish) were incubated in fresh medium for $18 \mathrm{~h}$, then stimulated with $10 \mu \mathrm{M}$ forskolin (Calbiochem) and 100 nM 12-O-tetradecanoylphorbol-13-acetate (TPA; Wako Chemicals) dissolved in dimethyl sulfoxide. Total RNA fractions were isolated from the cells $3 \mathrm{~h}$ later, using the acid guanidinium thiocyanate-phenol-chloroform method.

\section{RESULTS AND DISCUSSION}

\section{Isolation of $N G F I-B \quad c D N A$ isoform}

We previously isolated NOR-1, a member of the Nur77/NGFI-B family $(11,12)$. To further characterize the members of this family, we searched for variants of their gene products. By means of hybridization at low stringency with probes encoding sequences corresponding to the DNAbinding domain of human NOR-1, we isolated a novel cDNA variant of NGFI-B, designated NGFI-B2, from a human skeletal muscle $\lambda$ gt11 cDNA library.

Fig. 1 shows the cDNA sequences of human NGFI-B2. The size of the cDNA insert is 1813 nucleotides and it contains a major open reading frame of $978 \mathrm{nt}$ starting with an initiation codon at $182 \mathrm{nt}$. From ATG (at $180 \mathrm{nt}$ ) until $1057 \mathrm{nt}$, it was identical to NGFI-B, but the 5' and 3' non coding regions completely differed (Fig. 2). The divergent points of the cDNA were identical to the boundary between exons (2), indicating that this variant is an isoform generated by alternative splicing. The NGFI-B2 reading frame was followed by a 3' untranslated region of $654 \mathrm{nu}$ cleotides. No canonical AATAAA sequence was found, indicating that the sequence of $1813 \mathrm{nu}$ cleotides lacked information for a 3 ' end. An ATTTA motif, which may facilitate selective mRNA degradation or destabilization by removal of the poly(A) tail (16), is present in most Nur77/NGFI-B family members $(1,4,9$, 15), whereas the NGFI-B2 3'-sequences did not contain this motif. This suggested that stability of the NGFI-B2 mRNA may differ from that of other members of the Nur77/NGFI-B family. The predicted NGFI-B protein sequence revealed that it had sequences identical to that of NGFI-B at the transactivating domain, but lacked the $\mathrm{C}$ -terminal amino acid sequences corresponding to the putative ligand-binding or dimerizing domain. A receptor for 9-cis retinoic acid, RXR, forms heterodimers with NGFI-B, and its growth factor-induced immediate-early gene products are implicated as modulators of the retinoic acid signaling pathway (15). Since NGFI-B2 protein lacked the putative dimerizing domain, it may compete with the NGFI-B-RXR heterodimer. Furthermore, while the steroid/thyroid receptor superfamily members contain two zinc-fingers, NGFI-B2 had only one of the C2-C2 type. This suggested that NGFI-B2 does not bind to the NGFI-B response element (NBRE; 5'-AAAAGGTCA-3').

$N G F I-B 2$ and NGFI-B expression in human tissues

We investigated NGFI-B2 and NGFI-B expres- 


\begin{tabular}{|c|c|}
\hline $\begin{array}{l}\text { CAGGGCT } \\
\text { GACCTIT }\end{array}$ & \\
\hline 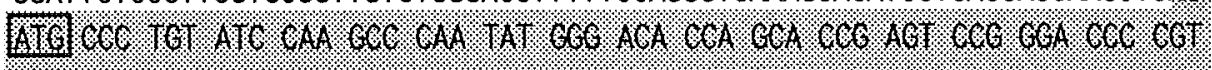 & \\
\hline 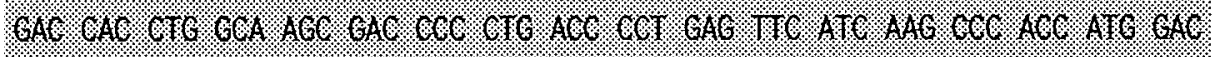 & \\
\hline 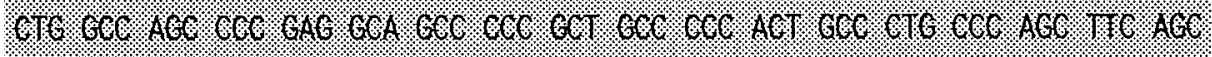 & \\
\hline 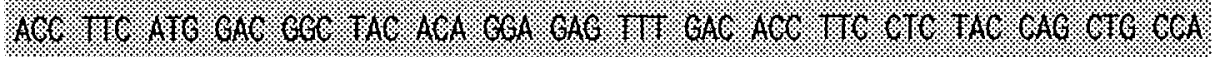 & \\
\hline 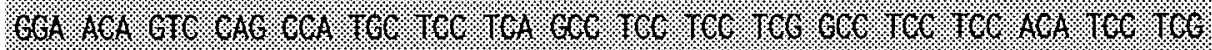 & \\
\hline 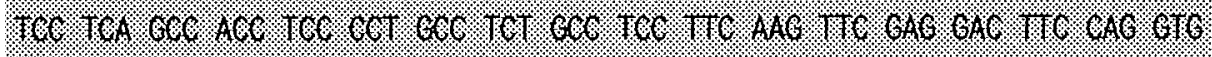 & \\
\hline 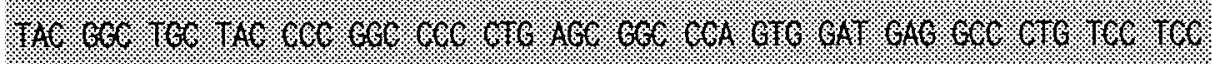 & \\
\hline 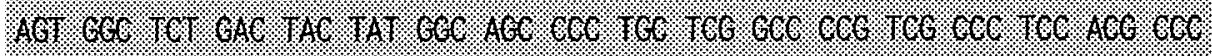 & \\
\hline 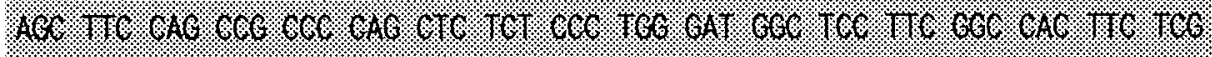 & \\
\hline 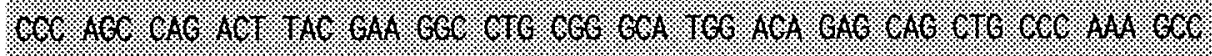 & \\
\hline 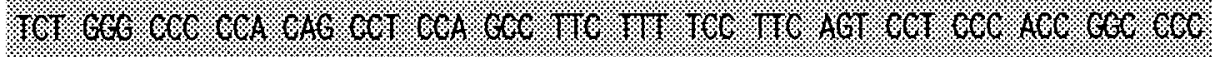 & \\
\hline 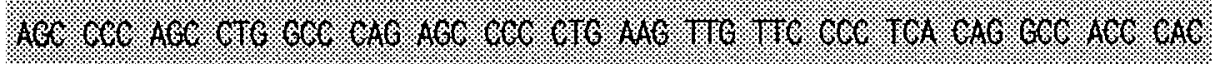 & \\
\hline 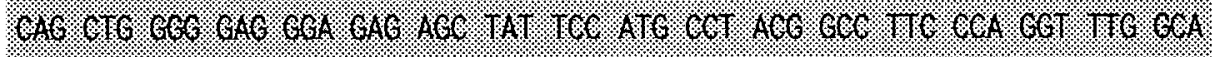 & \\
\hline 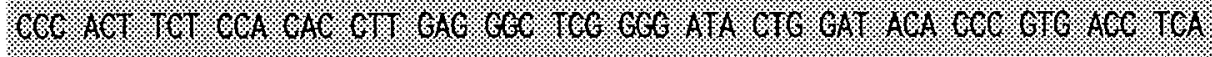 & \\
\hline 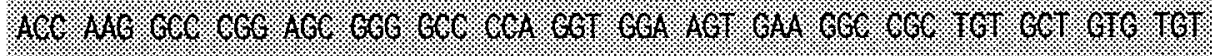 & \\
\hline 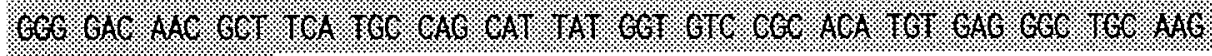 & \\
\hline 36.11\% 110.88 GTA CCG CGC AGC CCC AGG & \\
\hline GGG ACC & \\
\hline $\begin{array}{l}\text { GT } \\
\text { TC } \\
\text { GA } \\
\text { AT } \\
\text { GC } \\
\text { GT } \\
\text { CA } \\
\text { GC }\end{array}$ & \\
\hline
\end{tabular}

Fig. 1 Nucleotide sequence of human NGFI-B2 cDNA. The numbers on the right refer to the nucleotide sequence. The initiator and terminator are boxed. A region found in both NGFI-B2 and NGFI-B is shadowed.

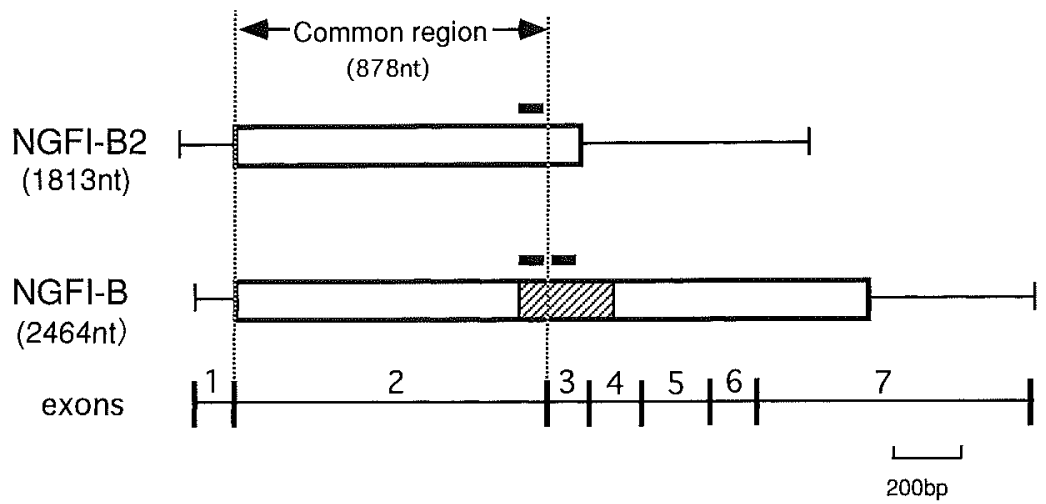

Fig. 2 Comparison of NGFI-B2 and NGFI-B cDNAs. The boundaries of NGFI-B exons are shown at the bottom. The boxes and bars are represent the major open reading frames and zinc-finger motifs, respectively. The shadowed box indicates the DNA-binding domain. 
sion in various tissues by means of RT-PCR. We detected NGFI-B in skeletal muscle, fetal brain and placenta at a similar intensity, whereas NGFI-B2 was found only in skeletal muscle (Fig. 3). PCR amplification with primers designed from the G3PDH cDNA sequence as a control was not changed in any of the tissues examined. The tissue-specific expression of NGFI-B2 and NGFI-B suggested that they have different functions. Other members of the Nur77/NGFI-B family, NOR-1 and RNR-1, also have an isofor$\mathrm{m}$, but they are concomitantly expressed with their original transcripts (unpublished results). The NGFI-B gene might have a high level of transcriptional complexity.
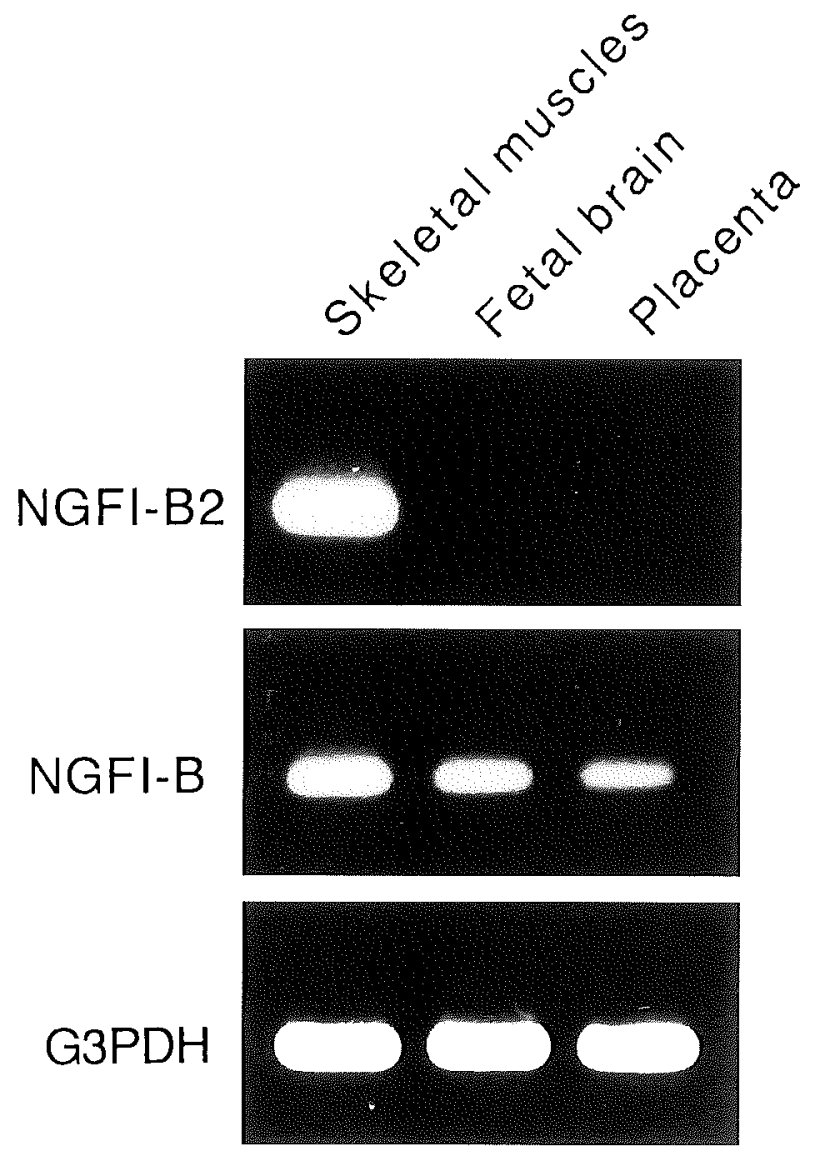

Fig. 3 Reverse-transcriptase-PCR analysis of NGFI-B isoforms. NGFI-B2, NGFI-B and G3PDH cDNAs, synthesized using RNAs from the indicated sources, were amplified by means of PCR. The products were resolved by electrophoresis on agarose gels.
NGFI-B2 and NGFI-B induction in human cells

To determine whether or not NGFI-B2 mRNA is induced by stimulation, we examined the effect of TPA and forskolin in human neuroblastoma (NB-OK-1) and breast cancer (MCF7) cells. NGFI-B was used as a positive control because it is identified as a TPA and/or forskolin inducible gene in neuroblastoma cells (8). TPA and forskolin rapidly induced the transcripts of NGFI-B, but not of NGFI-B2, in both NB-OK-1 and MCF7 cells (Fig, 4). PCR amplification of the G3PDH cDNA sequence as a control was not changed in any samples. Although all members of the Nur77/NGFI-B family (NGFI-B, RNR-1 and NOR-1) are defined as immediate-early genes (8), our results suggested that NGFI-B2 may not be associated with immediate-early responses. However, we cannot rule out the possibility that a small amount of NGFI-B2, which was not detected by RT-PCR, is induced in those cells, or that NGFI-B2 is induced in other cell types. The differential transcription regulation of NGFI-B isoforms and the two unique 5'-ends also suggest that this gene has two promoters, similar to those described for the RARs and RXRs $(5,6)$.

The complexity of the organization and expression of the NGFI-B gene is reminiscent of that of other key developmental genes. This complexity may serve to generate several regulatory factors from a single gene through alternative splicing and multiple promoters. Since there are multiple isoforms of NOR-1 and RNR-1, the functional differences between these isoforms of the Nur77/ NGFI-B family should be determined.

In conclusion, we identified and characterized a human NGFI-B2 cDNA isoform, which encodes a common core amino acid sequence corresponding to the transactivating domain, and which has a unique 5'-untranslated region and lacks a putative ligand-binding domain. The expression and regulation of NGFI-B isoforms suggested that these variants play different roles in biological processes. Since the NGFI-B gene is implicated in important biological processes including apoptosis, $\mathrm{G}_{0} / \mathrm{G}_{1}$ transition and neural development, detailed studies of NGFI-B isoforms are crucial to determine the molecular mechanisms of these processes. 


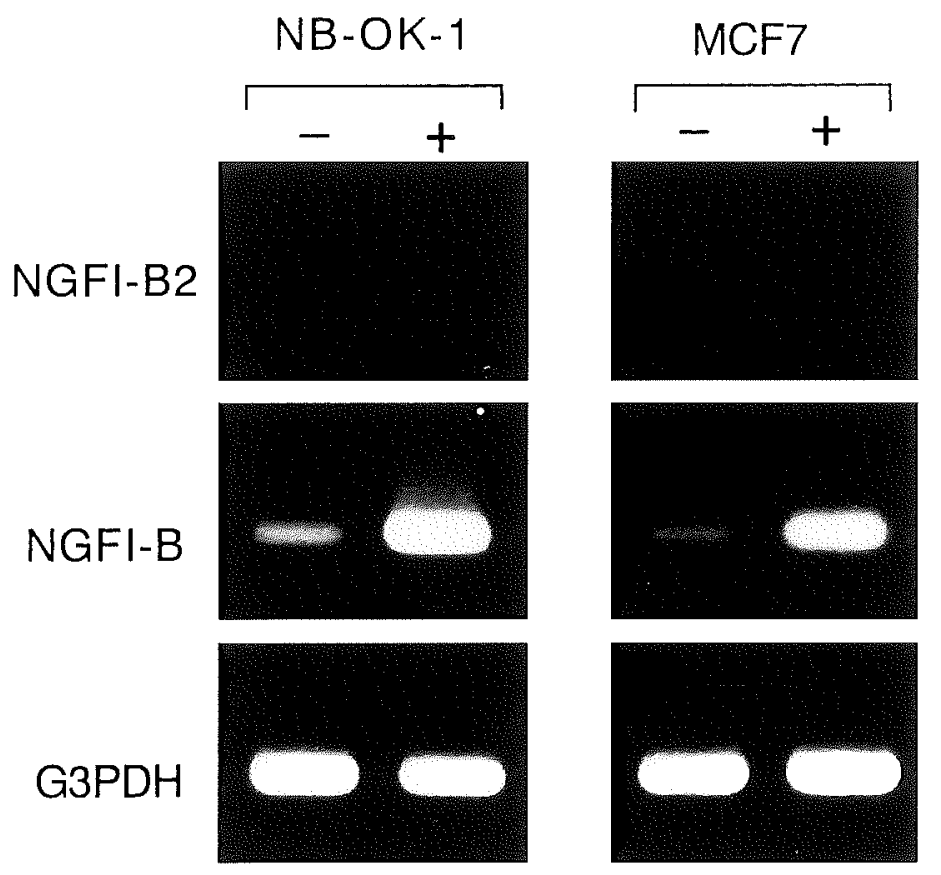

Fig. 4 Effect of forskolin and TPA on gene expression of NGFI-B2, NGFI-B and G3PDH in human neuroblastoma (NB-OK-1) and breast cancer (MCF7) cells. Cells were stimulated with forskolin (10 $\mu \mathrm{M})$ and TPA (100nM) for $3 \mathrm{~h}$. Total RNA fractions were amplified by RT-PCR. $[-]$ : non-treated control, $[+]$ : exposed to forskolin and TPA.

\section{REFERENCES}

1. Chang C., Kokontis J., Liao S. S. and Chang Y. (1989) Isolation and characterization of human TR3 receptor: a member of steroid receptor superfamily. J. Steroid Biochen. 34, 391-395.

2. Chang C., Saltzman A., Lee H.-J., Uemura H., Su C., Chodak G., Nakamoto T., Le Beau M. M., Espinosa R., Davis E., Lemons R. S., Sivak L. and Shih C. (1993) Genomic structure, chromosomal localization and expression of an androgen inducible TR3 orphan receptor: a member of the steroid receptor superfamily. Endocr. J. 1, 541-549.

3. Davis I. J. and Lau L. F. (1994) Endocrine and neurogenic regulation of the orphan nuclear receptors Nur77 and Nurr-1 in the adrenal glands. Mol. Cell. Biol. 14, 34693483.

4. Hazel T. G., Nathans D. and Lau L. F. (1988) A gene inducible by serum growth factors encodes a member of the steroid and thyroid hormone receptor superfamily. Proc. Natl. Acad. Sci. USA 85, 8444-8448.

5. Kastner P., Krust A., Mendelsohn C., Garnier J. M., Zelent A., Leroy P., Staub A. and Chambon P. (1990) Murine isoforms of retinoic acid receptor $\gamma$ with specific patterns of expression. Proc. Natl. Acad. Sci. USA 87, 2700-2704.

6. Liu Q. and Linney E. (1993) The mouse retinoid-X receptor- $\gamma$ gene: genomic organization and evidence for functional isoforms. Mol. Endocrinol. 7, 651-658.

7. Liu Z. G., Smith S. W., McLaughlin K. A., Schwartz L. M. and Osborne B. A. (1994) Apoptotic signals delivered through the T-cell receptor of a T-cell hybrid require the immediate-early gene nur77. Nature 367, 281-284.

8. Maruyama K., Tsukada T., Bandoh S., Sasaki K., Ohkura N. and Yamaguchi K. (1995) Expression of NOR-1 and its closely related members of the steroid/thyroid hormone receptor superfamily in human neuroblastoma cell lines. Cancer Lett. 96, 117-122.

9. Milbrandt J. (1988) Nerve growth factor induces a gene homologous to the glucocorticoid receptor gene. Neuron 1, 183-188.

10. Nakai A., Kartha S., Sakurai A., Toback F. G. and DeGroot L. J. (1990) A human early response gene homologous to murine nur77 and rat NGFI-B, and related to the nuclear receptor superfamily. Mol. Endocrinol. 4, $1438-1443$.

11. Ohkura N., Hijikuro M., Yamamoto A. and Miki K. (1994) Molecular cloning of a novel thyroid/steroid receptor superfamily gene from cultured rat neuronal cells. Biochem. Biophys. Res. Commun. 205, 1959-1965.

12. Ohkura N., Ito M., Tsukada T., Sasaki K., Yamaguchi K. and Miki K. (1996) Structure, mapping and expression of a human NOR-1 gene, the third member of the Nur77/ NGFI-B family. Biochim. Biophys. Acta 1308, 205-214.

13. Parkes D., Rivest S., Lee S., Rivier C. and Vale W. (1993) Corticotropin-releasing factor activates c-fos, NGFI-B, and corticotropin-releasing factor gene expression within the paraventricular nucleus of the rat hypothalamus. Mol. Endocrinol. 7, 1357-1367.

14. Perlmann T. and Jansson L. (1995) A novel pathway for vitamin A signaling mediated by RXR heterodimerization with NGFI-B and NURR1. Genes \& Dev. 9, 769-782. 
15. Ryseck R. P., Macdonald B. H., Mattei M. G., Ruppert S. and Bravo R. (1989) Structure, mapping and expression of a growth factor inducible gene encoding a putative nuclear hormonal binding receptor. EMBO J. 8, 3327-3335.

16. Shaw G. and Kamen R. (1986) A conserved AU sequence from 3' untranslated region of GM-CSF mRNA mediates selective mRNA degradation. Cell 46, 659-667.

17. Watson M. A. and Milbrandt J. (1989) The NGFI-B gene, a transcriptionally inducible member of the steroid receptor gene superfamily: genomic structure and expression in rat brain after seizure induction. Mol. Cell. Biol. 9, 42134219.

18. Wilson T, W., Fahrner T. J., Johnston M. and Milbrandt J. (1991) Identification of the DNA binding site for
NGFI-B by genetic selection in Yeast. Science 252, 12961300.

19. Woronicz J. D., Calnan B., Ngo V. and Winoto A. (1994) Requirement for the orphan steroid receptor Nur77 in apoptosis of T-cell hybridomas. Nature 367, 277-281.

\section{FOOTNOTE}

The nucleotide sequence data reported in this paper will appear in the DDBJ, EMBL and GenBank nucleotide sequence database with the following accession number D85245. 